\title{
Mating system in a neotropical tree species, Senna multijuga (Fabaceae)
}

\author{
Renata Acácio Ribeiro and Maria Bernadete Lovato \\ Universidade Federal de Minas Gerais, Instituto de Ciências Biológicas, \\ Departamento de Biologia Geral, Belo Horizonte, MG, Brazil.
}

\begin{abstract}
Senna multijuga is a pioneer tropical tree species that occurs mainly in the Brazilian Atlantic forest. We investigated the mating system of two populations of $S$. multijuga, one located in a reserve area (RD1) and the other (RD2) about $15 \mathrm{~km}$ away. The mating system parameters were estimated using the mixed mating model (software MLTR). The two populations had significantly different outcrossing rates, with population RD2 having a high rate $\left(t_{m}=0.838\right)$ and population RD1, a lower rate $\left(t_{m}=0.540\right)$. The values of $t_{s}$ were different between the two populations and also lower than those of $t_{m}$. Significant $t_{m}-t_{s}$ estimates indicated that biparental inbreeding contributed to the apparent selfing rate in these populations. The correlation of paternity was significant in population RD2 $\left(r_{p}=0.309\right)$, suggesting that the progeny were more closely related than inferred by the observed outcrossing rate. The estimates of correlation of paternity, biparental inbreeding and the significant differences in pollen and ovule allele frequencies indicated that population RD2 is genetically substructured. For a pioneer species such as $S$. multijuga, selfing can be an important strategy for occupying open areas.
\end{abstract}

Key words: isozymes, mating systems, neotropical tree, Senna multijuga.

Received: July 3, 2003; Accepted: November 27, 2003.

\section{Introduction}

The long-term survival of a species depends on the ability of populations to respond to environmental changes and is related to the amount of genetic variation present in the species (Beardmore, 1983). The mating system has an important influence on the amount and distribution of genetic variation within and among populations of plant species (Hamrick et al., 1979; Loveless and Hamrick, 1984; Hamrick and Godt, 1989). Several factors can affect the mating system, including population size and density (Murawski and Hamrick, 1992; Routley et al., 1999; Franceschinelli and Bawa, 2000), mode of pollination, availability of pollinators and their foraging behavior (Murawski, 1995; Franceschinelli and Bawa, 2000), flowering synchrony and phenological patterns (Boshier et al., 1995; Hall et al., 1996), the degree of genetic structuring of the population (Ennos and Clegg, 1982; Franceschinelli and Bawa, 2000) and the presence of a self-incompatibility system (Murawski and Hamrick, 1992; Lee, 2000). Several studies have shown spatial and temporal variation in the mating system of certain tree populations (Murawski and Hamrick, 1991, 1992; Liengsiri et al., 1998; Coates and

Send correspondence to Maria Bernadete Lovato. Universidade Federal de Minas Gerais, Instituto de Ciências Biológicas, Departamento de Biologia Geral, CP 486, 31270-901 Belo Horizonte, MG, Brazil. E-mail: lovatomb @icb.ufmg.br.
Hamley, 1999; Rocha and Aguilar, 2001). In contrast, Neel et al. (2001) studied six populations of Eriogonum ovalifolium and found no significant relationship between mating system parameters and environmental conditions or plant density. Collevatti et al. (2001) reported outcrossing rates of 1 for four Caryocar brasiliense populations analyzed, which suggested that this species had an efficient self-incompatibility mechanism. In another study, Hall et al. (1996) found no difference in the outcrossing rates among populations of Pithecollobium elegans that differed in their proportion of flowering trees in two consecutive years.

Habitat fragmentation can also affect the mating system of remnant populations by promoting reproductive isolation through a reduction in the effective population size and alterations in pollen dispersal patterns (Saunders et al., 1991; Young et al., 1996). Reproductive isolation, loss of genetic variability caused by drift and mating between closely related individuals would increase the frequency of inbreeding (Templeton et al., 1990; Young et al., 1996; Cruzan, 1998). Lee (2000) reported a lower outcrossing rate for populations of Drybalanops aromatica in a logged forest than in a primary forest, probably because of the lower density of flowering trees and changes in the foraging behavior of pollinators.

Plant species show a large variety of mating systems that range from highly selfing to exclusively outcrossing. 
Most tropical species are predominantly outcrossed, with outcrossing rates higher than 0.80 (Murawski, 1995; Doligez and Joly, 1997; Nason and Hamrick, 1997). However, inbreeding does occur in populations of some tropical species and may arise by selfing or by mating among related individuals (biparental inbreeding). The latter may reflect the spatial genetic substructure of the population (Ennos and Clegg, 1982) caused by the limited dispersal of pollen and/or seeds (Turner et al., 1982) and/or variation in the flowering synchrony among individuals (Hall et al., 1996). Inbreeding increases the frequency of homozygotes leading to detrimental effects, which are called inbreeding depression (Wright, 1965).

Cassia, originally treated as a large, heterogeneous genus and sole representative of the subtribe Cassiinae (tribe Cassineae, Caesalpinioideae, Fabaceae), was divided by Irwin and Barneby (1982) into the genera Cassia, Senna and Chamaecrista. Senna multijuga (Rich.) Irwin \& Barneby, popularly known in Brazil as "canafístula" or "pau-cigarra", is a medium-sized leguminous tree found in various South American countries (Irwin and Barneby, 1982). In Brazil, S. multijuga occurs mainly in the Atlantic forest, where it is a pioneer species adapted to poor soils and is suitable for mixed plantations used in the regeneration of degraded areas (Lorenzi, 1992; Carvalho, 1994). Senna multijuga has composite leaves and hermaphroditic flowers with yellow petals grouped in terminal multiple panicles. Flowering occurs from December to March and mature fruit occur from April to November, depending on the location (Carvalho, 1994). The plane seeds show autochoric dispersion and are part of the soil seed bank (Carvalho, 1994). Several Senna species are pollinated by bees of different genera and species (Gottsberger and Silberbauer-Gottsberger, 1988). Chromosomal counts for S. multijuga indicates $\mathrm{n}=12$, suggesting that the species is polyploid (Irwin and Turner, 1960).

Considering the importance of S. multijuga for regeneration of degraded areas, as well as the influence of the mating system on the genetic variation of plant populations, we used allozyme genetic markers to estimate some mating system parameters in two populations of this species.

\section{Material and Methods}

\section{Population sampling}

Two populations of $S$. multijuga were sampled, one located inside (RD1) and the other outside (RD2) the Rio Doce State Park (19 $48^{\prime}$ S, $42^{\circ} 38^{\prime}$ W), a biological reserve that is the largest remnant of Brazilian Atlantic forest $(\sim 36,000 \mathrm{ha})$ in the State of Minas Gerais, southeast Brazil. Population RD1 is located in an area of secondary vegetation within the boundaries of the park and population RD2, in an area of pasture surrounding the park, $15 \mathrm{~km}$ from RD1. Trees with a sufficient number of seeds for the study were randomly sampled in the populations. These trees were separated by a minimum of $3 \mathrm{~m}$ in each population. Ten open-pollinated seeds were sampled from 22 trees in the RD1 population and 20 seeds from 14 trees in the RD2 population, to give a total of 220 and 280 seeds per population, respectively. According to Ritland (1996), a progeny number of 200 is sufficient for a good estimate of outcrossing. The offspring from a single maternal tree are referred to here as a family or progeny array. The seeds were stored in dry conditions and required mechanical scarification with sandpaper to promote germination.

\section{Isozyme extraction and electrophoresis}

The seeds were germinated on filter paper in Petri dishes for $48 \mathrm{~h}$ at $28 \pm 1^{\circ} \mathrm{C}$ in the dark. Subsequently, seedlings with roots about $1 \mathrm{~cm}$ long were crushed in extraction buffer containing $0.1 \mathrm{M}$ Tris- $\mathrm{HCl}, \mathrm{pH} 7.5,0.2 \mathrm{M}$ sucrose, $1 \mathrm{mM}$ EDTA, $0.6 \%$ polyvinylpyrrolidone (PVP), $0.1 \%$ bovine serum albumin (BSA) and $0.1 \% \beta$-mercaptoethanol (Sun and Corke, 1992). The extracts were absorbed onto filter paper wicks and placed into $12 \%$ starch gels. Horizontal electrophoresis was done at a constant current of $40 \mathrm{~mA}$ at $5{ }^{\circ} \mathrm{C}$ for approximately $5 \mathrm{~h}$. Several running buffers and 14 enzyme systems were tested using the protocols described by Soltis et al. (1983) and Alfenas (1998) in order to obtain a maximum number of markers for the study. The following five enzyme systems showed polymorphism and clear band resolution that allowed unequivocal genetic interpretation: aspartate aminotransferase (AAT, EC 2.6.1.1), alcohol dehydrogenase (ADH, EC 1.1.1.1), 6-phosphate dehydrogenase (6PGD, EC 1.1.1.44), phosphoglucomutase (PGM, EC 2.7.5.1) and shikimate dehydrogenase (SKDH, EC 1.1.1.25). Electrophoresis of these enzymes was done using Tris-citrate gel and electrode buffer (Sun and Corke, 1992).

The genetic interpretations of the banding patterns in gels were based on typical subunit structures, as reported previously for other plant species (Kephart, 1990; Alfenas, 1998). For enzyme systems with more than one zone of activity, the most anodal zone (locus) was numbered "1", with the remaining loci numbered sequentially. The alleles for each locus were identified in a similar fashion: the most anodal allele was designated as "a", followed by the remaining alleles.

\section{Determination of the mating system}

The mating system parameters were estimated using the multilocus mating system program MLTR (Ritland, 1996), based on the mixed mating model proposed by Ritland and Jain (1981). This model is based in the following assumptions: (1) each mating event is due to random outcrossing (with probability $t$ ) or self-fertilization $(s=1$ $t$ ), (2) the probability of outcrossing is independent of the maternal genotype, (3) the pollen pool is homogeneous over all maternal trees, (4) there is no selection between fertilization and the time of assay for progeny genotypes, and 
(5) alleles at different loci segregate independently (Ritland and Jain, 1981).

The parameters estimated from the progeny array data were the multilocus outcrossing rate $\left(t_{m}\right)$, the average single-locus outcrossing rate $\left(t_{s}\right)$, the biparental inbreeding rate $\left(t_{m}-t_{s}\right)$ and the correlation of paternity $\left(r_{p}\right)$ or proportion of full sibs among outcrossed progeny. These parameters were estimated using maximum likelihood procedures. The Newton-Raphson method was used to solve the likelihood equation for the maximum likelihood estimates, as recommended by Ritland (1996). Neighborhood size, i.e., the number of pollen donors contributing to each family, was estimated as $1 / r_{p}$ (Ritland, 1989). The inbreeding coefficient of maternal parents $\left(F_{m}\right)$ was also calculated using the program MLTR (Ritland, 1996). The $t_{m}$ and $t_{s}$ values were compared in order to assess the degree of biparental inbreeding. In the absence of biparental inbreeding, the values will be the same, whereas in the presence of biparental inbreeding, $t_{s}$ will be lower than $t_{m}$ because outcrossing events that are not detected at a single locus have a higher probability of being detected as more loci are examined (Ritland, 1990). The standard errors for these parameters were calculated from 500 bootstraps with resampling among families. Comparison of the parameters between populations was done using Student's $t$-test. To determine whether the values were significantly lower than one $\left(t_{m}\right.$ and $\left.t_{s}\right)$ or greater than zero $\left(F_{m}, t_{m}-t_{s}\right.$ and $\left.r_{p}\right)$, mean $\pm 1.96 \mathrm{X}$ SE (standard error) was used.

The pollen and ovule allele frequencies were estimated for each locus using the expectation-maximization method (MLTR; Ritland, 1996). Differences between these frequencies were tested by the chi-square test of heterogeneity: $\chi^{2}=2 N \mathrm{~F}_{\mathrm{ST}}(a-1), \mathrm{df}=(a-1)$, where $N$ is the number of seeds examined, $a$ is the number of alleles at the locus, and $F_{S T}$ is a measure of the genetic diversity between the pollen and ovule pools (Murawski and Hamrick, 1992; Hall et al., 1994).

\section{Results}

\section{Genetic interpretation of the enzyme systems}

The polymorphic banding patterns of the six enzyme systems studied in the $S$. multijuga populations are shown in Figure 1. In population RD1, two banding zones (loci) were seen in gels stained for AAT, each with two alleles (Figure 1a). In population RD2, these loci had fixed alleles. The two loci (Aat-1 and Aat-2) had identical banding patterns that resulted in identical frequencies of the alleles. This suggests that these loci are probably linked and represent a recent duplication. Since the multilocus mixed mating model presupposes that alleles at different loci segregate independently, among the Aat loci only the Aat-1 was used to analyze the mating system. For ADH, the banding patterns revealed two loci ( $A d h-1$ and $A d h-2$ ), each one with three alleles forming intra- and inter-locus hetero- a) $A T T$

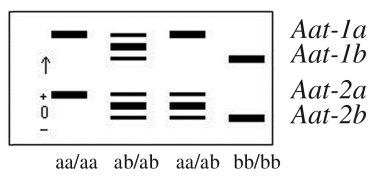

c) $6 P G D$

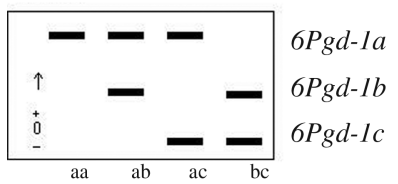

e) $\mathrm{ADH}$

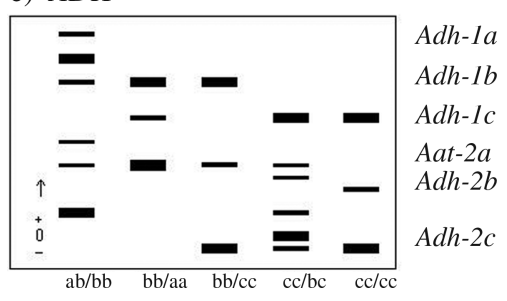

Figure 1 - The electrophoretic phenotypes and corresponding genotypes for five enzyme systems used to analyze the mating system in populations of Senna multijuga.

dimers (Figure 1e). These banding patterns probably resulted from the duplication of polymorphic loci (Gottlieb, 1982). This enzyme system showed a clear genetic interpretation only in population RD2. Staining for PGM revealed two loci (Pgm-1 and Pgm-2) in both S. multijuga populations (Figure 1b). However, only the Pgm-2 locus had good band resolution, with three alleles. Finally, 6PGD and SKDH showed only one locus each (6Pgd and Skdh) with three and four alleles, respectively (Figure 1c and 1d). However, these enzyme systems were not used to analyze the mating system in the two $S$. multijuga populations since the $6 P g d$ locus showed poor band resolution in population $\mathrm{RD} 2$ and the $S k d h$ locus stained only two alleles (Skdh-a and $S k d h-c$ ) in population RD1, with $S k d h-a$ being rare. In summary, three (Aat-1, 6Pgd and Pgm-2) and four loci (Adh-1, Adh-2, Pgm-2 and $S k d h$ ) were used to estimate the mating system parameters in RD1 and RD2, respectively.

To our knowledge, these loci are the first genetic markers identified in S. multijuga. Considering the marked phenotypic diversity present in this species (Irwin and Barneby, 1982), these markers may be useful for taxonomical and population genetic studies.

\section{Mating system}

The multilocus $\left(t_{m}\right)$ and single-locus $\left(t_{s}\right)$ outcrossing rates for the $S$. multijuga populations are shown in Table 1. The outcrossing rates were significantly lower than $1\left(t_{m}+\right.$ $1.96 \mathrm{SE}<1)$ in both populations. Population RD2 had a high outcrossing rate $\left(t_{m}=0.838\right)$, with a low percentage of self-fertilization. In contrast, population RD1 had a lower outcrossing rate $\left(t_{m}=0.540\right)$ with about $54 \%$ of the mating 
Table 1 - Mating system parameters in two populations of Senna multijuga. The parameters examined included the multilocus outcrossing rate $\left(t_{m}\right)$, mean single-locus outcrossing rate $\left(t_{s},\right)$, biparental inbreeding rate $\left(t_{m}-t_{s}\right)$, correlation of paternity $\left(r_{p}\right)$, neighborhood size and inbreeding coefficient of maternal parents $\left(F_{m}\right)$. Standard errors are shown in parentheses.

\begin{tabular}{lcc}
\hline Parameter & RD1 & RD2 \\
\hline N. families & 22 & 14 \\
N. progeny & 220 & 280 \\
$t_{m}$ & $0.540(0.090)$ & $0.838(0.068)$ \\
$t_{s}$ & $0.490(0.084)$ & $0.727(0.081)$ \\
$t_{m}-t_{s}$ & $0.051(0.016)$ & $0.111(0.036)$ \\
$r_{p}$ & $0.249(0.153)$ & $0.309(0.156)$ \\
Neighborhood & 4.0 & 3.2 \\
$F_{m}$ & $0.194(0.187)$ & $-0.030(0.195)$ \\
\hline
\end{tabular}

attributable to outcrossing and $46 \%$ attributable to selffertilization. These values were significantly different (Students $t$-test, $\mathrm{p}<0.05$ ). The values of $t_{s}$ were also significantly different between the populations and were lower than $t_{m}$ in both of them. There were marked differences in the outcrossing rates among families in the populations. In population $\mathrm{RD} 1$, the outcrossing rates ranged from zero to 2 and $86 \%$ of the families had $t_{m}<0.80$ (data not shown). In population $\mathrm{RD} 2$, the outcrossing rates ranged from 0.23 to 2.00 and only $43 \%$ of the families had $t_{m}<0.80$ (data not shown). Estimates of $t_{m}$ close to 2.00 are an artifact of the Newton-Raphson algorithm used in the computer analysis.

The positive differences between $t_{m}$ and $t_{s}$ were significantly different from zero in both $S$. multijuga populations $\left(t_{m}-t_{s}-1.96 \mathrm{SE}>0\right)$ (Table 1), indicating that biparental inbreeding contributed to the apparent selfing rate in populations of $S$. multijuga. Inbreeding coefficients of maternal parents $\left(F_{m}\right)$ were not significantly different from zero $\left(F_{m}-1.96 \mathrm{SE}=0\right)$ in both $S$. multijuga populations because of the high level of error in the estimates (Table 1). The estimates for correlation of paternity $\left(r_{p}=0.249\right.$ and 0.309 , Table 1 ) were significantly different from zero $\left(r_{p}-1.96 \mathrm{SE}>0\right)$ only in population RD2. However, these estimates did not differ between the populations ( $t$-test) because of the high error values. These $r_{p}$ values indicated that less than four fathers contributed to individual progeny arrays in the $S$. multijuga populations.

The estimates of pollen and ovule allele frequencies of the loci selected for mating system analyses in the $S$. multijuga populations are shown in Table 2 . The allele frequencies of all loci of population RD1 were homogeneous, suggesting that flowering trees contributed nearly equally to reproduction through pollen and ovules. However, there were significant differences between the pollen and ovule allele frequencies for two out of four loci in population RD2 (Skdh and $A d h-2)$, indicating that the pollen pool was not homogeneous over all maternal trees and thus violating the mixed mating model (Table 2).

\section{Discussion}

In contrast to the high outcrossing rate for population $\mathrm{RD} 2$ of $S$. multijuga (0.838), population RD1 had a lower outcrossing rate $\left(t_{m}=0.540\right)$. The average outcrossing rate for the two populations $\left(t_{m}=0.689\right)$ and the rate in population RD1 were lower than those reported for most tropical and neotropical tree species, which are predominantly outcrossers, such as Cordia alliodora $\left(t_{m}=0.966\right.$; Boshier et al., 1995), Tachigali versicolor $\left(t_{m}=0.998\right.$; Loveless et al., 1998), Pterocarpus macrocarpus $\left(t_{m}=0.719-0.959\right.$; Liengsiri et al., 1998), Shorea leprosula $\left(t_{m}=0.837\right.$; Lee et al., 2000), Caryocar brasiliense ( $t_{m}=1.000$; Collevatti et al., 2001). However, some species have a similar or lower $t_{m}$ than that observed in population RD1, e.g. Ceiba pentandra $\left(t_{m}=0.689\right)$, Eucalyptus rhodantha $\left(t_{m}=0.59\right.$ $0.65)$, Cavanillesia platanifolia $\left(t_{m}=0.213-0.569\right)(\mathrm{Mu}-$ rawski, 1995), Helicteres brevispira $\left(t_{m}=0.478-0.676\right.$; Franceschinelli and Bawa, 2000). In pioneer species, selffertilization is considered a strategy to ensure reproduction during the colonization of new habitats by one or a few individuals (Stebbins, 1974). Thus, the capacity for selffertilizing probably represents an important strategy for the colonization of open areas by S. multijuga, as also suggested for Helicteres brevispira (Franceschinelli and Bawa, 2000).

The outcrossing rates of the two $S$. multijuga populations were significantly different. Variation in outcrossing rates among populations has been reported for several plant species and probably reflects genetic and environmental differences among populations (Liengsiri et al., 1998; Coates and Hamley, 1999; Lee, 2000). Liengsiri et al. (1998) suggested that the differences in outcrossing rates seen among 11 populations of Pterocarpus macrocarpus were attributable to the degree of habitat disturbance and the density and distribution of flowering trees. Although population RD2 of S. multijuga is located in a more disturbed area than is population RD1, it had a significantly greater level of outcrossing and a similar level of biparental inbreeding when compared to RD1. The density of these populations was not measured, although apparently there was not much difference between them. Since $S$. multijuga is a pioneer species, the degree of environment disturbance probably did not affect its mating system. Differences in the degree of flowering synchrony and in the phenological patterns or in the level of self-compatibility among populations of $S$. multijuga could account for the variation seen in the extent of outcrossing. These characteristics may reflect the influence of genetic and/or environmental factors. Genetic factors in particular may have produced differences in the outcrossing rates of these two populations since both showed considerable genetic divergence, with several alleles found in one but absent in the other population (Table 2 and data not shown).

The pollen and ovule allele frequencies were significantly different in two out of four loci in the RD2 popula- 
Table 2 - Pollen and ovule allele frequencies for populations of Senna multijuga and $\chi^{2}$-test results for the differences between these frequencies. $F_{S T}$ is the genetic difference between populations. Standard errors are shown in parentheses.

\begin{tabular}{|c|c|c|c|c|c|c|}
\hline Populations & Locus & Allele & Pollen & Ovule & $F_{S T}\left(10^{-3}\right)$ & $\chi^{2}$ \\
\hline \multirow[t]{8}{*}{ RD1 } & Aat-1 & a & $0.103(0.047)$ & $0.159(0.058)$ & & \\
\hline & & $\mathrm{b}$ & $0.897(0.047)$ & $0.841(0.058)$ & 6.886 & 3.016 \\
\hline & Pgm-2 & $\mathrm{a}$ & $0.009(0.007)$ & $0.022(0.016)$ & & \\
\hline & & $\mathrm{b}$ & $0.974(0.017)$ & $0.956(0.016)$ & & \\
\hline & & $\mathrm{c}$ & $0.017(0.012)$ & $0.022(0.000)$ & 1.900 & 1.672 \\
\hline & $6 P g d$ & a & $0.591(0.123)$ & $0.659(0.074)$ & & \\
\hline & & $\mathrm{b}$ & $0.252(0.099)$ & $0.250(0.076)$ & & \\
\hline & & $\mathrm{c}$ & $0.157(0.051)$ & $0.091(0.040)$ & 4.229 & 3.722 \\
\hline \multirow[t]{13}{*}{ RD2 } & Adh-1 & $\mathrm{a}$ & $0.004(0.000)$ & $0.034(0.000)$ & & \\
\hline & & $\mathrm{b}$ & $0.725(0.097)$ & $0.724(0.096)$ & & \\
\hline & & $\mathrm{c}$ & $0.271(0.097)$ & $0.241(0.096)$ & 1.100 & 1.228 \\
\hline & Adh-2 & $\mathrm{a}$ & $0.004(0.003)$ & $0.034(0.000)$ & & \\
\hline & & $\mathrm{b}$ & $0.550(0.064)$ & $0.448(0.060)$ & & \\
\hline & & $\mathrm{c}$ & $0.446(0.064)$ & $0.517(0.060)$ & 7.876 & $8.790^{*}$ \\
\hline & Pgm-2 & $\mathrm{a}$ & $0.091(0.032)$ & $0.071(0.041)$ & & \\
\hline & & $\mathrm{b}$ & $0.869(0.037)$ & $0.893(0.046)$ & & \\
\hline & & $\mathrm{c}$ & $0.040(0.017)$ & $0.036(0.025)$ & 1.149 & 1.286 \\
\hline & Skdh & $\mathrm{a}$ & $0.359(0.038)$ & $0.448(0.077)$ & & \\
\hline & & $\mathrm{b}$ & $0.553(0.042)$ & $0.414(0.085)$ & & \\
\hline & & $\mathrm{c}$ & $0.071(0.020)$ & $0.103(0.048)$ & & \\
\hline & & d & $0.017(0.011)$ & $0.034(0.000)$ & 11.994 & $20.149^{* *}$ \\
\hline
\end{tabular}

$* \mathrm{p}<0.05$ and $* * \mathrm{p}<0.001$

tion. One assumption of the mixed mating model is that the allele frequencies in the pollen and ovule pools are homogeneous (Ritland and Jain, 1981). Several factors could account for the departure from this model, including unequal male and female contributions among adult trees within the populations, pollen coming from outside of the population, selection between the time of pollination and progeny sampling and/or nonrandom mating of genotypes during outcrossing events (Murawski and Hamrick, 1992; Doligez and Joly, 1997; Lee et al., 2000). In S. multijuga, the differences between the pollen and ovule allele frequencies (population RD2), as well as the significant level of biparental inbreeding $\left(t_{m}-t_{s}\right)$, suggested that there was either mating among relatives or positive assortative matings as the result of genetic structuring of the population (Ritland and Jain, 1981; Ennos and Clegg, 1982). The wide range of outcrossing rates among families in both $S$. multijuga populations provided further evidence that population RD2 is genetically substructured. However, the $t_{m}$ estimates of families must be interpreted cautiously because of the small sample sizes within families, particularly in population RD1.

The correlation of paternity was relatively high and significantly greater than zero in population RD2. Thirtyone percent of the outcrossed progeny pairs within a family were full sibs, indicating that less than four fathers contributed to the pollination of each maternal plant. This correlation indicated that progeny were more closely related to each other than inferred from the observed outcrossing rate. The level of correlated mating seen in S. multijuga was comparable to the $r_{p}$ values in the endangered shrub Labertia orbifolia (Coates and Hamley, 1999), but was lower than that in the emergent canopy tree Dryobalanops aromatica (Lee, 2000), in the endangered subshrub Eriogonum ovalifolium (Neel et al., 2001) and in some tropical tree species (James et al., 1998). The level of correlated mating reinforces the hypothesis that population RD2 is genetically substructured and would explain the low pollen flow. Although $S$. multijuga is probably pollinated by bees (Gottsberger and Silberbauer-Gottsberger, 1988), we have no information about the behavior of the pollinators on flowering individuals. Franceschinelli and Bawa (2000) have shown that variation in pollinator behavior, plant density, and number of flowers per plant can alter mating system parameters.

In conclusion, the mating system in $S$. multijuga is dynamic, with variable outcrossing rates among individuals and populations. This variation may be an important adaptation to ensure reproduction in different environmental conditions. 


\section{Acknowledgements}

The authors thank Rosângela L. Brandão for help in the fieldwork, Ana Carolina S. Ramos and Marlene de Miranda for their technical assistance, and Dr. Cesar Jacoby for revising the English of the manuscript. R.A.R. was supported by a fellowship from the Conselho Nacional de Desenvolvimento Científico e Tecnológico (CNPq, Brazil). This work was supported by Fundação de Amparo à Pesquisa do Estado de Minas Gerais (FAPEMIG, Brazil).

\section{References}

Alfenas AC (1998) Eletroforese de Isoenzimas e Proteínas Afins: Fundamentos e Aplicações em Plantas e Microrganismos. Editora UFV, Viçosa, MG, 574 pp.

Beardmore JA (1983) Extinction, survival and genetic variation. In: Schonewald-Cox CM, Chambers SM, MacBryde B and Thomas WL (eds) Genetics and Conservation. Benjamin Cummings, Menlo Park, pp 125-151.

Boshier DH, Chase MR and Bawa KS (1995) Population genetics of Cordia alliodora (Boraginaceae), a neotropical tree. 2. Mating system. Am J Bot 82:476-483.

Carvalho PER (1994) Espécies Florestais Brasileiras: Recomendações Silviculturais, Potencialidades e Usos da Madeira. EMBRAPA, Centro Nacional de Pesquisa de Florestas, Brasília, DF, 640 pp.

Coates DJ and Hamley VL (1999) Genetic divergence and the mating system in the endangered and geographically restricted species, Lambertia orbifolia Gardner (Proteaceae). Heredity 83:418-427.

Collevatti RG, Grattapaglia D and Hay JD (2001) High resolution microsatellite based analysis of the mating system allows the detection of significant biparental inbreeding in Caryocar brasiliense, an endangered tropical tree species. Mol Ecol 86:60-67.

Cruzan MB (1998) Genetic markers in plant evolutionary ecology. Ecology 79:400-412.

Doligez A and Joly HI (1997) Mating system of Carapa procera (Meliaceae) in the French Guiana tropical forest. Am J Bot 84:461-470.

Ennos RA and Clegg MT (1982) Effect of population substructuring on estimates of outcrossing rate in plant population. Heredity 48:283-292.

Franceschinelli EV and Bawa KS (2000) The effect of ecological factors on the mating system of a South American shrub species (Helicteres brevispira). Heredity 84:116-123.

Gottlieb LD (1982) Conservation and duplication of isozymes in plants. Science 216:373-380.

Gottsberger G and Silberbauer-Gottsberger I (1988) Evolution of flower structures and pollination in neotropical Cassiinae (Caesalpiniaceae) species. Phyton (Austria) 28:293-320.

Hall P, Orrell LC and Bawa KS (1994) Genetic diversity and mating system in a tropical tree, Carapa guianensis (Meliaceae). Am J Bot 81:1104-1111.

Hall P, Walker S and Bawa KS (1996) Effect of forest fragmentation on genetic diversity and mating system in a tropical tree, Pithecellobium elegans. Conserv Biol 10:757-768.

Hamrick JL and Godt MJW (1989) Allozyme diversity in plant species. In: Brown AHD, Clegg MT, Kahler AL and Weir
BS (eds) Plant Population Genetics, Breeding and Genetic Resources. Sinauer, Sunderland, pp 43-63.

Hamrick JL, Linhart YB and Mitton JB (1979) Relationship between life history characteristic and electrophoretically detectable genetic variation in plants. Annu Rev Ecol Syst 10:173-200.

Irwin MS and Barneby RC (1982) The American Cassiinae. A synoptical revision of Leguminosae tribe Cassieae subtribe Cassiinae in the New World. Mem N Y Bot Gard 35:1-918.

Irwin MS and Turner BL (1960) Chromosomal relationships and taxonomic considerations in the genus Cassia. Am J Bot 47:309-318.

James T, Vege S, Aldrich P and Hamrick JL (1998) Mating systems of three tropical dry forest tree species. Biotropica 30:587-594.

Kephart SR (1990) Starch gel electrophoresis of plant isozymes: A comparative analysis of techniques. Am J Bot 77:693712.

Lee SL (2000) Mating system parameters of Dryobalanops aromatica Gaertn. F. (Dipterocarpaceae) in three different forest types and a seed orchard. Heredity 85:338-345.

Lee SL, Wickneswari R, Mahani MC and Zakri AH (2000) Mating system parameters in a tropical tree species, Shorea leprosula Miq. (Dipterocarpaceae), from Malysian lowland dipterocarp forest. Biotropica 32:693-702.

Liengsiri C, Boyle TJB and Yeh FC (1998) Mating system in Pterocarpus macrocarpus Kurz in Thailand. J Hered 89:216-221.

Lorenzi H (1992) Árvores Brasileiras. Manual de Identificação e Cultivo de Plantas Arbóreas Nativas do Brasil. Plantarum Ltda, Nova Odessa, 348 pp.

Loveless MD and Hamrick JL (1984) Ecological determinants of genetic structure in plant populations. Annu Rev Ecol Syst 15:65-95.

Loveless MD, Hamrick JL and Foster RB (1998) Population structure and mating system in Tachigali versicolor, a monocarpic neotropical tree. Heredity 81:134-143.

Murawski DA (1995) Reproductive biology and genetics of tropical trees from a canopy perspective. In: Loman $\mathrm{M}$ and Nadkarni N (eds) Forest Canopy. Academic Press, New York, pp 457-493.

Murawski DA and Hamrick JL (1991) The effect of the density of flowering individuals on the mating systems of nine tropical tree species. Heredity 67:167-174.

Murawski DA and Hamrick JL (1992) Mating system and phenology of Ceiba pentandra (Bombacaceae) in Central Panama. J Hered 83:401-404.

Nason JD and Hamrick JL (1997) Reproductive and genetic consequences of forest fragmentation: Two case studies of neotropical canopy trees. J Hered 88:264-276.

Neel MC, Ross-Ibarra J and Ellstrand NC (2001) Implications of mating patterns for conservation of the endangered plant Eriogonum ovalifolium var. vineum (Polygonaceae). Am J Bot 88:1214-1222.

Ritland K (1989) Correlated matings in the partial selfer, Mimulus guttatus. Evolution 43:848-859.

Ritland K (1990) A series of FORTRAN programs for estimating plant-mating systems. J Hered 81:235-237.

Ritland K (1996) MLTR: Multilocus mating system program. Version 1.1. Available from the author. 
Ritland K and Jain SK (1981) A model for the estimation of outcrossing rate and gene frequencies using $\mathrm{n}$-independent loci. Heredity 47:35-52.

Rocha OJ and Aguilar G (2001) Variation in the breeding behavior of the dry forest tree Enterolobium cyclocarpum (Guanacaste) in Costa Rica. Am J Bot 88:1600-1606.

Routley MB, Mavraganis K and Eckert CG (1999) Effect of population size on the mating system in a self-compatible, autogamous plant, Aquilegia canadensis (Ranunculaceae). Heredity 82:518-528.

Saunders DA, Hobbs RJ and Margules CR (1991) Biological consequences of ecosystem fragmentation: A review. Conserv Biol 5:18-32.

Soltis DE, Haufler CH, Darrow DC and Gastony GJ (1983) Starch gel electrophoresis of ferns: A compilation of grinding buffers, gel and electrode buffers, and staining schedules. Am Fern J 73:9-27.
Stebbins GL (1974) Flowering Plants. Evolution Above the Species Level. Harvard University Press, Cambridge, MA, 399 pp.

Sun M and Corke H (1992) Population genetics of colonizing success of weedy rye in northern California. Theor Appl Genet 83:321-329.

Templeton AR, Shaw K, Routman E and Davis SK (1990) The genetic consequences of habitat fragmentation. Ann Missouri Bot Gard 77:13-27.

Turner ME, Stephens JC and Anderson WW (1982) Homozygosity and patch structure in plant populations as a result of nearest neighbor pollination. Proc Natl Acad Sci USA 79:203-207.

Wright S (1965) The interpretation of population structure by F-statistics with special regard to systems of mating. Evolution 19:395-420.

Young A, Boyle T and Brown T (1996) The population genetic consequences of habitat fragmentation for plants. Trends Ecol Evol 11:413-418.

Associate Editor: Marcio de Castro Silva Filho 